UDK: 334.012.64:001.897.4

Pregledni rad
POSLOVNA EKONOMIJA BUSINESS ECONOMICS

Godina XII

Broj 1

Str $256-275$

doi: 10.5937/poseko13-15686

Prof. dr David Jovović, vanredni profesor

Univerziteta u Prištini, Poljoprivredni fakultet sa privremenim sedištem u Lešku

\title{
MODEL OTVORENIH INOVACIJA I RAZVOJ MALIH I SREDNJIH PREDUZEĆA
}

SAŽETAK: U savremenim uslovima poslovanja, znanje predstavlja ključnu ekonomsku kategoriju, posebno zbog značaja njegove komercijalizacije $u$ inovacije. Jer, sve je očiglednije da razlike $\mathrm{u}$ dostignutom nivou inovativnosti određuju u značajnom stepenu razvojne mogućnosti preduzeća, kao i privreda u celini. Inoviraj ili nestani, postala je suština poslovne politike preduzeća u posledljoj deceniji minulog veka. Imajući u vidu činjenicu da od tog vremena do današnjih dana, mala i srednja preduzeća sve više poprimaju atribute pokretača rasta nacionalne proizvodnje i ukupne zapslenosti, jasno je da je imperativ unapređenja njihove inovativnosti u ovom periodu došao do punog izražaja. Ovo iz osnovnog razloga, što inovativna mala i srednja preduzeća značajno doprinose prevladavanju tehnološkog jaza nacionalnih ekonomija, odnosno doprinose njihovom prelasku iz nižeg u viši nivo tehnološkog razvoja. U radu je apostrofirana važnost koncepta otvorenih inovacija za unapređenje inovativnosti i rast i razvoj malih i srednjih preduzeća. Omogućujući proces intenzivne razmene znanja, sredstava i tehnologije između pojedinih ekonomskih aktera, koncept otvorenih inovacija je doprineo unapređenju inovativnosti sektora malih i srednjih preduzeća kao ključnog pokretača rasta njihove konkurentnosti u ekonomiji znanja. Inovacije su moćno sredstvo za nova mala i srednja preduzeća da uspešno uđu na tržište i promene postojeće stanje, omogućavajući istovremeno i postojećim preduzećima da unapređenjem inovativnosti održe ili poboljšaju svoj položaj na 
tržištu. Inovativna mala i srednja preduzeća učestvuju u protoku znanja u okviru inovacionih sistema, sve manje kao pasivni korisnici, a sve više kao značajan izvor znanja.

Ključne reči: znanje, mala i srednja preduzeća, inovacije, model otvorenih inovacija.

\section{UVOD}

U ekonomskim istraživanjima novijeg datuma, inovacijama se poklanja najveća moguća pažnja. To je razumljivo kada se ima u vidu činjenica da razlike $u$ dostignutom nivou inovativnosti određuju $u$ značajnom stepenu razvojne mogućnosti pojedinih preduzećai (Chesbrough i dr., 2014). Najkraće, u ekonomiji vođenoj znanjem, jedino privrede koje poseduju sposobnost efikasne transformacije znanja $u$ inovacije mogu da ostvare punu zaposlenost i zadovoljavajuću dugoročnu stopu rasta bruto domaćeg proizvoda po stanovniku (Atkinson i Ezell, 2014). Kompetentna politika inovacija podrazumeva uvažavanje mišljenja istraživača i inovatora, a takođe i stavova ekonomista i menadžera koji se u oceni inovacionih procesa dominantno rukovode logikom profita (Švarc, 2009).

Najčešće primenjivani model poslovanja preduzeća do kraja dvadesetog veka, podrazumevao je inovacione aktivnosti koje su najvećim delom bile determinisane vlastitim znanjima i raspoloživom tehnologijom (Sungjoo i dr., 2010). Realno govoreći, u takvom ambijentu, preduzeća nisu bila ni previše zainteresovana da menjaju uspešan način poslovanja i ustaljene odnose sa potrošačima. Tehnološka i organizaciona znanja kojim su raspolagala, po pravilu, su čuvana kao poslovna tajna (Greenhalgh i Rogers, 2011).

Dinamičan razvoj nauke i tehnologije, široka upotreba sve moćnije informaciono-komunikacione opreme, promena privredne strukture, sve izraženija mobilnost radne snage, promene u navikama, potrebama i željama potrošača, kao i čitav niz drugih događaja direktno i indirektno uslovljenih globalizacijom, doveli su u godinama poslednje decenije prethodnog veka do smanjenja relevantnosti ovakvog modela poslovanja. Sve više je na značaju dobijao novi, tzv. otvoreni model poslovanja. Model je podrazumevao proces intenzivne razmene ideja, znanja, sredstava i tehnologije između preduzeća. Uvažavao je neophodnost međusobnog povezivanja i saradnje između poslovnih subjekata sa ciljem smanjenja potencijalnih rizika po definiciji skupih istraživačkih i inovacionih aktivnosti (Rahman \& Ramos, 2011). Nov način poslovanja podrazumevao je ne samo konkurenciju, već saradnju putem uspostavljanja različitih oblika 
strateških partnerstava i mnogih drugih manje ili više formalizovanih oblika poslovne saradnje. Umrežavanje postaje imperativ rasta i razvoja preduzeća u mnogim visokotehnološkim industrijama (Enkel i dr., 2009) Afirmacija kooperativnih odnosa na novim osnovama posebno je značajna u oblastima istraživačkih aktivnosti kod kojih je razmena znanja postala osnova uspešnog inovacionog procesa (Lu i dr., 2015).

I ekonomski napredne privrede i zemlje u razvoju tokom poslednjih decenija se fokusiraju na unapređenje inovativnosti, nadmećući se globalno u privlačenju najsposobnijih pojedinaca i povećanju tržišnih udela. Informacioni tokovi i mreže se šire preko granica, na načine koji nisu mogli ni da se pretpostave u godinama pre pojave interneta, mobilne telefonije i komunikacionih mreža najrazličitijih nivoa i namena (OECD, 2010). Poslovni modeli se korenito redefinišu, dok se radna mesta intenzivno i suštinski redizajniraju.

U ovom periodu značajno je povećan broj malih i srednjih preduzeća (MSP) u većini zemalja. Premda pojava ovih poslovnih subjekata ,ne spada $\mathrm{u}$ nove fenomene poslovne stvarnosti, njihov ubrzani razvoj i posebno poslovna transformacija, svakako spadaju u red značajnijih razvojnih megatrendova poslednjih decenija prethodnog milenijuma“" (Pokrajac, 2004, str. 43).

Inovacioni potencijali MSP su od esencijalne važnosti za unapređenje konkurentnosti sektora u okviru koga ona posluju, a takođe i privrede u celini. Inovativna MSP sve su izraženiji izvor znanja u okviru tehnoloških, sektorskih, pa čak i nacionalnih inovacionih sistema. Stoga identifikovanje uslova koji omogućavaju implementaciju otvorenih inovacija predstavlja važnu premisu rasta produktivnosti i konkurentnosti ovih preduzeća (Grimaldi i dr., 2013).

Predmet istraživanja u ovom radu je model otvorenih inovacija i njegova važnost za razvoj sektora malíh i srednjih preduzeća. Cilj je da se sagleda značaj modela otvorenih inovacija za razvoj ovih poslovnih subjekata, a takođe i da se identifikuju najznačajnije prepreke koje stoje na putu njegove šire primene u malim i srednjim pruzećima.

$\mathrm{U}$ istraživanju su koriščeni kako induktivni tako i deduktivni metodi. Takođe, primenjivani su metodi deskripcije, analize i sinteze. Kritički su sagledavani rezultati brojnih radova sa tematikom modela otvorenih inovacija i razvoja malih i srednjih preduzeća, stranih i domaćih autora objavljenih u referentnoj stručnoj literaturi novijeg datuma. 


\section{PROIZVODNJA TEMELJENA \\ NA \\ KOMERCIJALIZOVANOG U INOVACIJE \\ ZNANJU}

Dvadesetprvi vek donosi snažan rast industrija vođenih inovacijama zahvaljujući afirmaciji najrazličitijih mreža koje postaju sredstvo pomoću kojeg preduzeća ujedinjuju ili razmenjuju resurse i zajednički rade na razvijanju novih ideja i sposobnosti. „Saradnja preduzeća u oblasti inovacija može da obuhvata zadatke od najjednostavnijih (zajednička nabavka potrebnih ulaza), do najsloženijih (saradnja na aktivnostima istraživanja i razvoja) u celokupnom procesu razvoja i komercijalizacije inovacija. Saradnjom je moguće smanjiti rizike i troškove, ali i povećati delotvornost inovacionih procesa, pa je zato ona često povezana sa njihovom uspešnom komercijalizacijom. Nivo saradnje zavisi od usklađenosti sredstava na raspolaganju, sposobnosti i poslovnih strategija partnera, što se odražava na jasnost zajednički postavljenih ciljeva i sposobnost uključenih preduzeća za njihovo ostvarivanje" (Cvijić i dr., 2012).

Savremena proizvodnja je sve više temeljena na upotrebi znanja komercijalizovanog u inovacije. U ekonomiji znanja, učenju i kreiranju znanja se pridaje najveća pažnja. Ovo i pored činjenice što sa aspekta teorije, paradigma ekonomije znanja još uvek nije ni izdaleka nedvosmisleno utemeljena u naučnom smislu. Pritom mnogi autori decidno zastupaju stav da još uvek nema objektivnih potvrda za njeno postojanje. Jer, kako oni primećuju, još uvek u tumačenju suštine privrednih aktivnosti dominantno se koristi analitički instrumentarij tradicionalne ekonomske teorije (Drašković i dr., 2013).

Novi oblici konkurencije redizajnirali su tržište znanja i inovacija u globalno tržište koje se razvija u suštinski novim pravcima. Sve veći troškovi istraživačkih i razvojnih aktivnosti u javnom i privatnom sektoru dovode do porasta ponude znanja, odnosno proizvodnja znanja postaje globalna industrija (Mroczkowski, 2012). Zauzvrat, globalna konkurencija naročito u sektorima novih tehnologija - nastavlja da povećava tražnju za znanjem. Zapravo, nastala je globalna trka oko tržišno atraktivnih inovacija $\mathrm{u}$ industrijama poput energetike, biofarmacije, novih materijala, elektronike. U tom nadmetanju, uključeno je mnoštvo institucija na različitim geografskim destinacijama na kojima se stvara novo znanje. Taj široki krug obuhvata privatne kompanije, sektore za konsalting, laboratorije u javnom vlasništvu, kao i mnogobrojne univerzitete. Sve te organizacije se takmiče u nalaženju što bržih i efikasnijih puteva do znanja koja se mogu pretvoriti u nove ili bolje proizvode i usluge za potrošače širom sveta (Narayanan, 2001). Ukratko, nove ideje komercijalizovane u inovacije predstavljaju ključnu premisu ekonomske uspešnosti preduzeća i zemalja. 
Osnovna odlika ekonomije temeljene na znanju je da ulaganje u obrazovanje, unapređenje inovativnosti, rastuća primena savremenih informacionih i komunikacionih tehnologija, kao i kreiranje podsticajnog poslovnog i institucionalnog ambijenta za rezultat ima veću upotrebu i stvaranje znanja u privredi, što omogućava zadovoljavajuću stopu ekononomskog rasta i zaposlenosti. U takvim uslovima privređivanja MSP predstavljaju pokretačku snagu rasta nacionalne proizvodnje zbog doprinosa zapošljavanju, povećanju izvoza, dinamiziranju konkurencije, itd. Inovativna MSP značajno doprinose prevladavanju tehnološkog jaza, odnosno prelasku iz nižeg u viši oblik proizvodne tehnologije. „Iako, principijelno, inovativnost, kao naročita vrsta težnje ka promenama predstavlja imanentan sadržaj svakog preduzetničkog ponašanja, za najnoviji uzlet MSP smatramo da je tehnološka inovativnost daleko najvažniji pokretač onih razvojnih promena zbog kojih uopšte MSP možemo smatrati svojevrsnom metaforom uspešnog poslovanja poslednjih decenija u najvećem delu razvijenog sveta“ (Pokrajac, 2004, str. 43-44).

\section{KONCEPT OTVORENIH INOVACIJA}

Međusobno zavisne i povezane, brojne tehnološke inovacije tokom poslednjih decenija donosile su velike promene mesta pojedinih zemalja na listi najrazvijenijih privreda u svetu. Ekonomije koje ne raspolažu prirodnim resursima mogu u današnjim uslovima privređivanja posedovati izuzetan ekonomski potencijal, zahvaljujući prvenstveno sposobnsti komercijalizacije znanja u inovacije (Mroczkowski, 2012). Takmičenje u kreiranju optimalnih inovacionih procesa se naročito intenziviralo tokom poslednjih četrdesetak godina.

Mnogi autori smatraju da se u periodu od polovine pa do kraja 20. veka promenilo pet generacija inovacija. Od pet modela, prva četiri pripadaju klasi zatvorenih inovacija budući da kod svih preduzeće vlastitim resursima realizuje inovacije. Model zatvorenih inovacija se zasnivao na nekoliko principa:

- investirajući u sopstveno istraživanje i razvoj, firma obezbeđuje dobre izglede za angažovanje najsposobnijih pojedinaca za određeni posao,

- da bi ostvarila profite po osnovu istraživanja i razvoja, preduzeća moraju da završe kompletan proces od razvoja do komercijalizacije inovacije,

- preduzeća treba strogo da kontrolišu vlastitu imovinu i onemoguće da konkurenti ostvare profit po tom osnovu (prednost prvog koraka), 
- preduzeća koja poseduju nove ideje i proizvode pobeđuju u konkurentskoj utakmici (Chesbrough, 2006).

Peta generacija reprezentuje model tzv. otvorenih inovacija (Chesbrough, 2006). Ovaj model efikasnije generiše inovacije s obzirom da on objedinjuje više talenata, kreativnosti i više novih ideja nego što bi to moglo biti moguće čak i nekoj velikoj korporaciji. Dobre ideje i pronalasci dolaze sa raznih neočekivanih mesta, od potrošača, dobavljača, partnera sa zajedničkim ulaganjima, pa čak i javnosti (Smith, 2010). Slobodno se može reći da je koncept otvorenih inovacija korenito promenio način inoviranja u kompanijama u ovom veku (Chesbrough, 2006) Jedan broj analitičara ide korak dalje tvrdeći da ovaj model predstavlja mnogo više od jednostavnog korišćenja tuđih ideja i tehnologije. On, po njima, predstavlja promenu u načinu korišćenja, upravljanja, zapošljavanja, kao i stvaranja intelektualne svojine u ekonomiji znanja (West i Gallagher, 2006, str. 351).

Model otvorenih inovacija nastaje u globalizovanom okruženju gde znanja zahvaljujući povezivanju (pre svega posredstvom Interneta) postaju široko dostupna i gde pojedinačna preduzeća (pre svih MSP) nemaju dovoljno resursa da samostalno realizuju neophodne istraživačke i razvojne aktivnosti. Takođe, interni pronalasci koji su rezultat inovacione aktivnosti preduzeća koje ona nisu u stanju da na dovoljno efikasan način komercijalno valorizuju mogu se plasirati izvan preduzeća ustupanjem licencnih prava, zajedničkim ulaganjima, itd. i time ostvariti dodatni prihod.

Model otvorenih inovacija podrazumeva da preduzeća mogu i treba da koriste eksterne ideje, znanja i tehnologije, na gotovo identičan način kao i interne ideje, znanja i tehnologije, isto kao i unutrašnje i spoljašnje metode za komercijalizaciju inovativnih rezultata na tržištu. I u modelu otvorenih inovacija, preduzeća mogu i dalje da iniciraju i neguju inovacije unutar preduzeća, ali u isto vreme mogu i da se oslanjaju na alternativne puteve da iznesu ideje na tržište i da imaju koristi od eksternog znanja (Vanhaverbeke, 2006). Zahvaljujući objedinjavanju stvaralačkog potencijala velikog broja ljudi, koncept otvorenih inovacija u ekonomiji znanja značajno doprinosi podizanju inovativnosti privrede kao celine.

Više je faktora koji su doveli do razvoja i primenu modela otvorenih inovacija. Očigledno da je tehnološki intenzitet proizvodnje povećan u mnogim granama, tako da čak ni preduzeća sa respektibilnim sektorom istraživanja i razvoja nisu u mogućnosti ili nisu spremna da se oslone samo na sopstveni tehnološki razvoj (Gassmann, 2006, str. 224) Inovacioni proces postaje sve složeniji, pri čemu rešavanje velikog broja složenih problema podrazumeva interdisciplinarni pristup istraživanju što, po pravilu, rezultira većim troškovima i izraženijim rizicima u procesu inoviranja (Howells i dr., 2003, str. 398) Zato je čest slučaj da preduzeća mnoga za njih manje važna 
istraživanja ili istraživanja iz oblasti gde nisu dovoljno kompetentna poveravaju drugim organizacijama, a da pritom i dalje sopstvenim snagama razvijaju tehnološka znanja u oblasti koja je za njih najznačajnija.

Prethodno eksplicirane generacije inovacija se ni u kom slučaju ne mogu tretirati kao konačne. Naprotiv, „sa velikom dozom uverenosti može se reći da će upravo kreativnost i inovativnost biti najcenjenija, kako lična tako i grupna legitimacija i najpouzdanija ,ulaznica za budućnost“" svakom budućem stanovniku ove jedine zemlje. Zbog toga, izvesno je neki budući analitičari ovih tema govoriće o šestoj, sedmoj, osmoj i ko zna kojoj svegeneraciji inovacija“" (Pokrajac, 2010).

Za razvoj koncepta otvorenih inovacija veliki značaj imaju i potrošači. Mnogi potrošači su inovativno orijentisani, teže da poboljšaju postojeće proizvode i usluge preduzeća i tako i sami postaju inovatori (Bogers i dr., 2010). Potrošači inovatori često eksperimentišu estetskim i funkcionalnim karakteristikama, namenom i načinom upotrebe postojećih proizvoda, daju ideje i početne faze razvoja novih proizvoda i usluga, predlažu nove forme odnosa preduzeća sa potrošačima, itd. Preduzeća tako uz pomoć svojih potrošača inovatora dolaze do odgovarajućih inovacionih rešenja i tako zadovoljavaju potrebe koje postoje na tržištu novim ili poboljšanim proizvodima ili uslugom.

Model otvorenih inovacija je izuzetno pogodan za primenu $u$ oblastima novih tehnologija gde veći broj preduzeća, među kojima su sve prisutnija MSP, istovremeno imaju i proizvode i usluge u svojoj ponudi. U nastojanju da održe korak sa konkurentima u dinamičnim granama privrede preduzeća često stvaraju odvojene organizacione jedinice koje prate otvorene inovacije i strategije koje se koncentrišu na inovacione projekte izvan osnovne delatnosti preduzeća. Ilustracije radi, kompanija Proktor i Gembl je kao jedan od osnovnih poslovnih ciljeva odredila da polovinu od ukupnih inovacija bitnih za proizvodnju, distribuciju i plasman proizvoda, transferiše iz eksternih izvora (Lichtenthaler, 2011). To na svijevrstan način govori o spremnosti kompanije da uspostavi strateški značajne veze sa subjektima koji poseduju znanje i sposobnosti koji su od suštinske važnosti za uspešnu realizaciju sve brojnijih inovacionih poduhvata. Paralelno, kompanija ulaže ogromna sredstva u vlastita istraživanja i razvoj kako bi povećala inovativnost $\mathrm{i}$ unapredila proces komercijalizacije rezultata istraživačkih i razvojnih aktivnosti u nove proizvode i nove proizvodne procese (Lichtenthaler, 2011). 
STR 256-275

\section{ZNAČAJ KONCEPTA OTVORENIH INOVACIJA ZA RAZVOJ MSP}

Savremena preduzeća ne moraju raspolagati najnovijim znanjima da bi uspela u sadašnjim uslovima. Ključ uspeha je u pravoj kombinaciji postojećih znanja sa raspoloživim eksternim znanjima njihova komercijalna valorizacija u inovacije (Curley i Salmelin, 2018). Ukoliko otvorena preduzeća žele da im znanje i informacije koje dolaze iz okruženja budu od koristi i doprinesu boljem funkcionisanju, ona moraju kontinuirano unapređivati vlastitu inovativnost. Spoljna znanja nemaju nikakvu upotrebnu vrednost za preduzeće ukoliko se ne integrišu i ne povežu sa unutrašnjim znanjima. Kvalitet tako dobijene mreže unutrašnjih i spoljnih znanja određuje kvalitet i efikasnost inovacionog potencijala preduzeća (Cvijić i dr., 2012, str. 76) To znači da preduzeća moraju da budu spremna za uspostavljanje strateški važnih veza sa drugim preduzećima koja imaju znanje, veštine i iskustvo koje im je neophodno za dalje razvijanje inovativnog procesa (Parida i dr., 2012).

Mogućnost da preduzeća do aplikativnih znanja i inovacija dođu korišćenjem spoljnih izvora uslovljena je sposobnošću i raspoloživosti dobavljača, odnosno razvijenošću i kvalitetu eksterne baze inovativnog znanja. Postojanje raspoloživih dobavljača koji mogu da ponude odgovarajući kvalitet (koji često prevazilazi kvalitet koji preduzeće može interno da postigne) omogućava preduzećima da pojedine funkcije u lancu vrednosti povere drugim preduzećima a da se ona bolje usredsrede samo na ove elemente lanca vrednosti koja su za njih najisplativiji ili koje mogu bolje da realizuju od drugih preduzeća na tržištu.

Zbog mobilnosti na tržištu rada, zaposleni mogu da napuste preduzeće, da pređu u drugo preduzeće ili da osnuju sopstveno preduzeće koje će finansirati samostalno ili putem zajedničkog ulaganja. Opasnost da radnici koji napuste preduzeće jednostavno sa sobom odnesu ključne elemente inovacionog procesa koji je do tada razvijan u preduzeću je realnost. To znači da druga (često konkurentna) preduzeća mogu doći do bitnih inovacionih znanja koja su razvijana u preduzeću (West i Gallagher, 2006, str. 319).

Sve veće prisustvo privatnog finansiranja stvara značajne rizike preduzećima koja se u velikoj meri oslanjaju na unutrašnje inovacije jer rastuće mogućnosti za zajednička ulaganja povećavaju sklonost pojedinih zaposlenih da osnivaju vlastita ili se pridružuju postojećim novoosnovanim preduzećima (Rigby i Zook, 2002, str. 83). Ovo iz razloga što smatraju da novoosnovana preduzeća najčešće nude povoljniji odnos u pogledu rizika i zarade. 
Inovativna preduzeća su ona preduzeća koja su uvela inovaciju u toku posmatranog perioda, pri čemu inovacije ne mora da ostvari komercijalni uspeh. Inovativna preduzeća se mogu se podeliti na ona koje su inovacije pretežno samostalno razvila ili u saradnji sa drugim preduzećima ili javnim istraživačkim organizacijama, kao i na preduzeća koja inoviraju pretežno preuzimanjem inovacija (npr. nove opreme) koju su razvila druga preduzeća. Inovativna preduzeća takođe se mogu razlikovati prema vrstama realizovanih inovacija. U skladu sa tim, postoje inovativna MSP koja su realizovala nove proizvode ili procese, nove marketinške metode ili organizacione promene (UNESCO, 2009, str. 28).

Inovativno aktivna preduzeća su preduzeća koja su imala inovativne aktivnosti u posmatranom periodu, uključujući i tekuće i napuštene inovativne aktivnosti. Drugim rečima, preduzeća koja su imala inovativne aktivnosti u posmatranom periodu, bez obzira na to da li je aktivnost rezultirala realizacijom inovacija, smatraju se inovativno aktivnim preduzećima. Potencijalno inovativna preduzeća su vrsta inovativno aktivnih preduzeća, koja su učinila inovativne napore, ali nisu postigla inovativne rezultate (OECD, 2005, str. 47). Ovo je ključni element inovacionih politika čiji je cilj da podstiču, olakšaju i pomognu preduzećima da budu inovativna.

Postoje i drugi načini definisanja i klasifikovanja inovativnih preduzeća u zavisnosti od potreba istraživanja. Razlikovanje preduzeća prema inovativnosti može se koristiti da bi se odredio procenat preduzeća (prema veličini, sektoru, zemlji ili na drugi način) koji predstavlja svaki od četiri tipa inovacija, ili procenat preduzeća koja su realizovala kombinovane inovacije, kao što su inovacije proizvoda i inovacije u marketingu ili inovacije procesa $\mathrm{i}$ organizacione inovacije. Klasifikacija prema inovativnom statusu može da sadrži i druge podatke, kao na primer podatke o stvaraocima inovacije. Na taj način se može odrediti koja su preduzeća samostalno razvila inovaciju, koja u saradnji sa drugim preduzećima i/ili istraživačkim organizacijama, a koja su preuzela gotovo inovativno rešenje.

Preduzeća mogu da imaju inovacione aktivnosti u posmatranom periodu a da zapravo ne realizuju inovaciju. Sve aktivnosti koje su uključene u razvoj ili realizaciju inovacija, uključujući i one koje su planirane da se realizuju u budućnosti, su inovacione aktivnosti. U posmatranom periodu, inovacione aktivnosti mogu biti: a) uspešne i da rezultiraju nastankom inovacije (mada inovacija ne mora da bude komercijalno uspešna), b) tekuće i da obuhvate sve inovativne aktivnosti koje su u toku i koje još uvek nisu dovele do primene inovacije i v) napuštene, odnosno inovativne aktivnosti koje su napuštene pre primene inovacije.

Prema obeležjima inovativnosti proizvodna mala i srednja preduzeća mogu se grupisati u nekoliko kategorija: niskotehnološka MSP, MSP koja 
imaju minimum tehnoloških sposobnosti, tehnološki kompetentna MSP, MSP koja mogu samostalno uspešno da realizuju istraživanja čiji je cilj stvaranje nove inovacije (Arnold i Thuriaux, 1997, str. 21).

MSP predstavljaju veliku i veoma heterogenu grupu preduzeća u pogledu inovacionih kapaciteta, motiva za inoviranje, inovacionih aktivnosti i inovacionih rezultata. U skladu sa tim, mala i srednja preduzeća se mogu svrstati u četiri velike grupe: inovacioni lideri, vodeći korisnici inovacija, potencijalni inovatori i neinovativna MSP (Tabela 1).

Tabela 1. - Podela MSP u zavisnosti od raspoloživih inovacionih kapaciteta

\begin{tabular}{|c|c|}
\hline $\begin{array}{c}\text { I } \\
\text { Inovacioni lideri } \\
1-3 \% \text { od ukupnog broja MSP } \\
\text { (ispod pet zaposlenih) }\end{array}$ & $\begin{array}{c}\mathbf{2} \\
\text { Vodeći korisnici inovacija } \\
10-15 \% \text { od ukupnog broja MSP } \\
\text { (ispod pet zaposlenih) }\end{array}$ \\
\hline $\mathbf{3}$ & $\mathbf{4}$ \\
$\begin{array}{c}\text { Potencijalni inovatori } \\
\text { oko 40\% od ukupnog broja MSP } \\
\text { (ispod pet zaposlenih) }\end{array}$ & $\begin{array}{c}\text { Neinovativna MSP } \\
\text { oko 40-45\% od ukupnog broja MSP } \\
\text { (ispod pet zaposlenih) }\end{array}$ \\
\hline
\end{tabular}

Izvor - OECD, 2000., str 209.

MSP inovacioni lideri i vodeći korisnici inovacija su preduzeća koja aktivno inoviraju i učestvuju sa manje od 20\% u ukupnom broju MSP. Od preostalih $80 \%$ MSP oko $40 \%$ njih ima potencijal da bude inovativno i predstavljaju potencijalne inovatore, a oko $40-45 \%$ MSP su neinovativna preduzeća.

Inovacioni lideri su mala i srednja preduzeća koja su usmerena na inovacije, imaju dovoljno potrebnih kapaciteta i svoj razvoj i poslovanje zasnivaju na razvoju novih superiornih proizvoda i usluga. Najčešće se radi o malim i mladim preduzećima.

Drugu grupu inovativnih MSP čine mala i srednja preduzeća koja su vodeći (prvi) korisnici inovacija (OECD, 2000). Premda poslovni subjekti iz ove grupe nemaju kapacitete da budu inovacioni lideri, svoj opstanak temelje na brzoj primeni najnovijih znanja i tehnologija i tako omogućavaju veću komercijalizaciju inovacionih rezultata. Preduzeća iz ove grupe se mogu podeliti u dve glavne podgrupe: MSP sa dovoljnim IR kapacitetom za samostalno inoviranje i MSP koja se više oslanjaju na tuđe IR kapacitete i inovacione rezultate. Ova MSP zapošljavaju značajan broj visokoobrazovanih stručnjaka; uvode barem jedan novi proizvod u proseku; brinu o zadovoljstvu potrošača i prepoznaju vrednost istraživanja tržišta; spremni su da sarađuju sa drugim preduzećima; retko dobijaju subvencije; uglavnom nemaju vlastite patente (OECD, 2000, str. 9). 
Treću grupu čine preduzeća potencijalni inovatori. Reč je o velikoj grupi preduzeća koja čini oko 40\% svih MSP. Radi se o preduzećima koja nisu previše inovativno orijentisana, postoje duži niz godina i pozicionirana su na tržištu, najčešće posluju u tradicionalnim delatnostima gde tehnološke promene nisu previše brze i radikalne, aktivno prate najznačajnije inovacije i usvajaju ih. Bez obzira što razvoj inovacija nije u centru njihove razvojne strategije, aktivno prate inovacione trendove na tržištu i spremna su da razviju i primene inovacije ukoliko im se ukaže prilika.

Četvrtu grupu čine MSP koja nemaju ambicije, kapacitete, mogućnosti i potrebu da inoviraju. Radi se o starim već dobro tržišno pozicioniranim preduzećima, najčešće iz oblasti niskotehnološke prerađivačke industrije, čiji opstanak nije ugrožen brzim tehnološkim razvojem. Ova preduzeća često koriste stare proizvodne procese, retko sarađuju sa drugim preduzećima, nemaju značajnije razvojne aktivnosti i retko lansiraju nove proizvode na tržište (Tabela 2).

Tabela 2. - Ključna obeležja različitih tipova MSP

\begin{tabular}{|c|c|c|c|}
\hline & Inovacioni lideri & $\begin{array}{c}\text { Vodeći korisnici } \\
\text { inovacija (dve } \\
\text { podgrupe: sa i bez } \\
\text { dovoljno } \\
\text { istraživačkih i } \\
\text { razvojnih } \\
\text { kapaciteta) } \\
\end{array}$ & $\begin{array}{c}\text { Tehnološki } \\
\text { sledbenici i } \\
\text { neinovatina } \\
\text { preduzeća }\end{array}$ \\
\hline Veličina & $\begin{array}{c}\text { Najčešće mala } \\
\text { preduzeća (40\% } \\
\text { ima manje od } 10 \\
\text { zaposlenih; } 23 \% \\
\text { ima više od } 250 \\
\text { zaposlenih) }\end{array}$ & & \\
\hline Sektor & $\begin{array}{c}\text { Uglavnom posluju u } \\
\text { oblastima: novih } \\
\text { tehnologija*, IKT, } \\
\text { usluga baziranih na } \\
\text { znanju }\end{array}$ & $\begin{array}{l}\text { Iz proizvodnih i } \\
\text { uslužnih sektora, } \\
\text { ali manje iz sektora } \\
\text { novih tehnologija }\end{array}$ & $\begin{array}{l}\text { Niskotehnološka } \\
\text { prerađivačka } \\
\text { industrija; ređe iz } \\
\text { uslužnih delatnosti }\end{array}$ \\
\hline Starost & $\begin{array}{l}\text { Mlađa preduzeća od } \\
\text { proseka (33\% } \\
\text { posluju manje od } 5 \\
\text { godina) }\end{array}$ & $\begin{array}{l}59 \% \text { su starija od } \\
10 \text { godina }\end{array}$ & $\begin{array}{l}64 \% \text { su starija od } 10 \\
\text { godina }\end{array}$ \\
\hline Pripadnost & $\begin{array}{c}\text { Uključuju } \\
\text { istraživanja na } \\
\text { univerzitetima i } \\
\text { laboratorijama }\end{array}$ & $\begin{array}{c}\text { U proseku ulažu } \\
\text { oko } 11 \% \text { svog } \\
\text { prometa u } \\
\text { aktivnosti } \\
\text { istraživanja i } \\
\text { razvoja }\end{array}$ & $\begin{array}{c}\text { U proseku ulažu } \\
\text { manje od 5\% } \\
\text { ukupnog prometa u } \\
\text { aktivnosti istraživnja } \\
\text { i razvoja }\end{array}$ \\
\hline
\end{tabular}


STR 256-275

\begin{tabular}{|c|c|c|c|}
\hline $\begin{array}{l}\text { Aktivnosti } \\
\text { istraživanja i } \\
\text { razvoja }\end{array}$ & $\begin{array}{l}\text { Značajno ulažu u } \\
\text { istraživanje ( } 75 \% \\
\text { ulažu više od } 20 \% \\
\text { svog prometa) }\end{array}$ & $\begin{array}{l}\text { U proseku ulažu } \\
\text { oko } 11 \% \text { svog } \\
\text { prometa u } \\
\text { aktivnosti } \\
\text { istraživanja i } \\
\text { razvoja }\end{array}$ & $\begin{array}{c}\text { U proseku ulažu } \\
\text { manje od 5\% } \\
\text { ukupnog prometa u } \\
\text { aktivnosti } \\
\text { istraživanja i razvoja }\end{array}$ \\
\hline
\end{tabular}

* Biotehnologija, elektronika i telekomunikacije, industrijske softverske aplikacije, novi materijali,

$$
\text { Izvor - OECD, 2000., str. } 9
$$

Podela malih i srednjih preduzeća prema inovacionom potencijalu je značajna, jer preduzeća iz različitih inovacionih grupa imaju različite potrebe za inoviranjem. Ova MSP se susreću sa različitim izazovima i problemima u svojim inovacionim aktivnostima. Povećanje inovacionih mogućnosti MSP moguće je samo ukoliko se prepozna i uvaži heterogenost inovacionih mogućnosti i potreba ovih poslovnih subjekata. To praktično znači da mere i instrumenti inovacione politike moraju biti prilagođeni svakoj posebnoj grupi MSP, uvažavajući njihove ciljeve, mogućnosti i potrebe za pomoći u inovacionim aktivnostima.

Uspešna strategija modela otvorenih inovacija za MSP treba da pronađe kreativne načine da iskoristi unutrašnje inovacije i raspoložive spoljne inovacije koje doprinose razvoju preduzeća. Kompetentna istraživanja sugerišu da koncept otvorenih inovacija poboljšava inovativne performanse MSP (Hossain, 2015). Ova preduzeća imaju određene prednosti u inovacionom procesu koje ih čini pogodnim partnerom za umrežavanje, jer obično su manje birokratski koncipirana i uopšte gledano često imaju veći motiv da budu uspešnija od velikih preduzeća (Pullen i dr., 2008).

Umrežavanjem se otklanjaju neke od prepreka koje stoje na putu generisanja inovacija u MSP, bez uništavanja njihovih ključnih prednosti. U tom smislu, jedan broj autora istražuje kako tržišne neizvesnosti doprinose rastućoj umreženosti MSP. Zaključak je da u situacijama kada inovacioni proces predstavlja kompleksni sistem koji prevazilazi okvire preduzeća, mreže omogućavaju uspešnu tehnološku kooperaciju sa vrlo izraženim sinergetskim efektima (De Bresson i Amesse, 1991).

Prednosti umrežavanja MSP uključuju: inovativne šanse, niže transakcione troškove, deljenje troškova, veću proizvodnu efikasnost. Mreže omogućavaju deljenje rizika, deljenje troškova učenja i drugih troškova, koji podržavaju tehnološku konvergenciju između preduzeća, što za rezultat ima rast efikasnosti proizvodnje, kao i ekonomiju obima. S obzirom na njihove integrisane procese proizvodnje, svako preduzeće se mora usmeriti na posebnu komponentu njihovog zajedničkog finalnog proizvoda, potpuniji pristup informacijama (Dirckinck-Holmfeld, 2009). 
MSP imaju ključnu ulogu u diverzifikaciji inovacija u oblastima koje nisu isuviše atraktivne za velika preduzeća. Ona ne retko svojim aktivnostima pomeraju granice proizvodnje i potrošnje $u$ potrazi za zanemarenim mogućnostima kreiranja novih radnih mesta i unapređenja produktivnosti rada (Michael i Palandjian, 2004). Međutim, zbog činjenice da je sposobnost ovih poslovnih subjekata da se takmiče na globalnim tržištima ograničena uslovima i unutar i van preduzeća, saradnja među preduzećima postala je značajno sredstvo pomoću koga ovi poslovni entiteti prevazilaze neke od prepreka. Saradnja između MSP i velikih preduzeća danas postaje veoma bitna snaga u mnogim industrijama.

Model otvorenih inovacija predstavlja odgovor na aktuelne zahteve u pogledu inovativnih aktivnosti preduzeća, pre svega u oblasti istraživanja i razvoja i zaštite i korišćenja intelektualne imovine od strane preduzeća. Model naglašava potrebu za većom saradnjom između različitih preduzeća koja umanjuje potencijalne rizike i troškove i istovremeno povećava efikasnost inovativnog procesa i bolje komercijalizovala ideje na tržištu. Model je posebno pogodan za MSP koja sada imaju mogućnost da udruživanjem ideja, inovativnih aktivnosti i sredstava značajnije utiču na kretanja na tržištu nego što je to ranije bio slučaj. U novim uslovima privređivanja posebno dolaze do izražaja prednosti koje su imanentne MSP kao što su fleksibilnost i brzina reagovanja na promene uslova na tržištu. Model omogućava skraćivanje vremena koje je potrebno za razvoj proizvoda i njegovu pojavu na tržištu. MSP imaju šansu da brzinom reagovanja značajno preteknu velika preduzeća i na taj način obezbede konkurentsku prednost (Filipović i dr., 2016).

Promene u poslovnom okruženju (rast prihoda, povećanje broja tržišnih niša, promene u tehnologiji i razvoj modela otvorenih inovacija) smanjile su strukturne nedostatke ovih poslovnih subjekata koje proističu iz njihove ograničene mogućnosti za primenu ekonomije obima, povećavajući značaj novih i MSP u inovacionom procesu. Inovativna MSP su postala najznačajniji razvojni potencijal savremene privrede. Međutim, zbog uslova $\mathrm{u}$ kojima posluju, nedovoljno podsticajnog poslovnog ambijenata koji nije $u$ dovoljnoj meri prilagođen imperativa rasta inovativnosti, veliki broj MSP ne prepoznaje značaj razvoja inovacija ili nema potrebne uslove da $\mathrm{u}$ potpunosti realizuje svoj inovacioni potencijal.

Dok su ranijim radovima o otvorenim inovacijama uglavnom bile opisivane velike kompanije, tokom poslednjih godina sve se više piše o njihovoj primeni u malim i srednjim preduzeća, naročito kada je reč o malim i srednjim preduzećima koja se povezuju putem franšiznih sistema. Ovo posebno zbog činjenice što komercijalna valorizacija eksternih inovacija često predstavlja suštinsku kompetenciju za brzo rastuća MSP (Gassmann, Enkel, Chesbrough, 2010). 
U ekonomskoj literaturi tokom prethodnih nekoliko godina se dosta pisalo o značaju koncepta otvorenih inovacija u razvoju tzv. softvera otvorenog koda i s tim povezanim usponom velikog broja malih i srednjih preduzeća. „Softver otvorenog koda je najbolji primer otvorenih inovacija zbog zajedničkog prava na korišćenje rezultirajuće tehnologije, kao i saradnje prilikom njenog razvoja. Softver otvorenog koda nastao je kao reakcija na vlasnički model softvera i uključuje kod koji može biti modifikovan i redistribuiran drugima, pri čemu se priznaje doprinos originalnog autora. Ovaj termin uključuje niz primera saradnje na razvoju softvera koji datiraju još iz 70-tih godina prošlog veka. Osnovna prava koja se prenose na one koji poseduju kopiju besplatnog softvera uključuju pravo korišćenja bez naknade, pravo proučavanja softverskog koda, pravo na njegovu modifikaciju i pravo na distribuiranje izmenjene ili neizmenjene verzije drugima bez ikakve nadoknade" (Getejanc i Stanojević, 2016, 2009). Valja napomenuti da je razvoj ovog oblika otvorenih inovacija omogućen najširom primenom alata i dostupnošću interneta, koji je, takođe, doprineo unapređenju inovativnosti malih i srednjih preduzeća.

\section{PREPREKE U PRIMENI MODELA OTVORENIH INOVACIJA U MSP}

Sektor MSP deluje kao integrator celokupnog inovacionog sistema (Cvetanović i dr., 2016). Budući da u ekonomiji znanja, MSP posluju u globalnom okruženju, neophodno je da uspostave saradnju kako sa većim preduzećima u cilju stvaranja boljih mogućnosti i većeg iskorišćenja njihovih kapaciteta, tako i sa drugim MSP iz iste ili različitih delatnosti, kao i sa istraživačkim centrima, institutima, laboratorijama, samostalnim istraživačima, univerzitetima i svim drugim subjektima koji mogu da doprinesu njihovom inovacionom razvoju. Povećanje globalne konkurencije i rast troškova aktivnosti istraživanja i razvoja primoravaju MSP da sarađuju sa spoljnim partnerima u cilju plasiranja novih proizvoda i usluga na tržištu pre svojih konkurenata. Istovremeno, inovacija će biti više prihvaćena ako korisnici proizvoda i usluga, bilo da se radi o drugim preduzećima ili individualnim potrošačima, sve više postaju uključeni u proces inovacija (De Backer, 2008).

Dva su aspekta saradnje MSP sa drugim učesnicima u inovativnom procesu. Prvi, postoji kretanje iznutra ka spolja, kada se postojeće tehnološke mogućnosti MSP koriste izvan preduzeća. Drugi, postoji kretanje spolja ka unutra u kome se spoljni izvori inovacija koriste za poboljšanje postojećeg inovativnog razvoja MSP. MSP kombinuju oba vida 
saradnje sa okruženjem u cilju unapređenja inovativnih performansi i maksimiziranjem koristi od inovacionih napora (De Vrande i dr., 2008).

Brojna ograničenja otežavaju primenu modela otvorenih inovacija $u$ MSP. Vreme i resursi su najvažnija ograničenja MSP u primeni modela otvorenih inovacija (Kathan i dr., 2014). Ova preduzeća imaju manjak resursa, tako da se njihov period planiranja odnosi najviše na srednji rok. Realna nemogućnost MSP da dugoročno planiraju značajno umanjuje mogućnost pristupa MSP rezultatima spoljnih istraživanja. MSP nije uvek lako da uđu u održiv lanac vrednosti na tržištu, jer se fokusiraju samo na kratkoročne tržišne promocije. Veoma često ona nemaju čak ni dobro razvijeno srednjoročno planiranje tražnje usled ograničenih resursa i nedostataka potrebne mreže kontakata. Problem može da predstavlja i vremensko nepodudaranje okvira istraživanja spoljnih partnera (npr. univerziteta) sa realnim potrebama MSP što ovim često ne dozvoljava agresivan nastup na tržištu u pravom trenutku i sa pravim proizvodom. MSP često imaju probleme povezane sa finansiranjem istraživačkog procesa, nedostatak kvalifikovanih kadrova i malu mogućnost za zamenu odgovarajućih proizvoda na tržištu, ograničene mogućnosti za plasiranje proizvoda i dr. Pored ovih postoji i veći broj drugih unutrašnjih i spoljnih prepreka kod inoviranja u MSP, što donekle umanjuje i otežava uspešnu primenu modela otvorene inovacije, ali nikako ne umanjuje značaj njegove primene za uspešan inovativni razvoj (Hanna i Walsh, 2002).

Inovativna MSP se susreću sa izraženim problemima u pogledu finansiranja, dostupnosti rezultata aktivnosti istraživačkih institucija, pristupu međunarodnom tržištu, administrativnim barijerama i mogućnosti angažovanja kvalifikovanih kadrova $\mathrm{i} d r$. Sve to stvara potrebu za sistemskim, dobro osmišljenim politikama i konkretnim programima podrške koji treba da omoguće MSP da iskoriste svoj razvojni i inovacioni potencijal.

Takođe, postoji neravnomerna raspodela inovacija u okviru sektora MSP između malog broja visoko inovativnih MSP sa velikim potencijalom za rast i velikog broja MSP koja nemaju izraženu inovativnu orijentaciju i veliki inovacioni potencijal. Zato u okviru politike podsticanja inovacija treba da postoji jasna razlika između ove dve grupe MSP, odnosno potrebno je razumeti i uvažiti njihovu različitost u uslovima poslovanja, načinima i motivima za inoviranje.

MSP se suočavaju sa značajnim preprekama i ograničenjima koja negativno utiču na njihov inovacioni potencijal. Pored internih, značajne prepreke inoviranju su eksterne prepreke, na koje MSP ne mogu direktno da utiču već su prisiljena da im se prilagođavaju. To su prepreke koje proizilaze iz institucionalnog i tržišnog ambijenta, koje pogađaju sva mala i srednja preduzeća na tržištu. 


\section{ZAKLJUČAK}

Savremena proizvodnja je sve više temeljena na upotrebi znanja komercijalizovanog u inovacije. U ekonomiji znanja, učenju i kreiranju znanja se pridaje najveća pažnja. Osnovna odlika ekonomije temeljene na znanju je da ulaganje u obrazovanje, unapređenje inovativnosti, primenu savremenih informacionih i komunikacionih tehnologija, kao i kreiranje podsticajnog poslovnog i institucionalnog ambijenta za rezultat ima veću upotrebu i stvaranje znanja u privredi, što omogućava zadovoljavajuću stopu ekonomskog rasta i zaposlenosti.

Modeli otvorenih inovacija razvijaju se od kraja dvadesetog veka. Odražavaju nastojanje iskorišćenja raspoloživih resurasa znanja i kreativnosti. Preferiraju rastuću pokretljivost radne snage, posebno visoko kreativne. Prihvataju širenja rizika poslovanja i otpočinjenja preduzetničkih poduhvata, što posebno odgovara razvoju sektora MSP. Ključne prednosti modela otvorenih inovacija su šire mogućnosti primene inovacija, kako sopstvenih tako i onih koje dolaze iz okruženja. Ovim se sugeriše poslovni model koji se svodi na opredeljenje da je kooperacija bolja od konkurencije. Model otvorenih inovacija pružaju velike mogućnosti svim akterima uključujući MSP, ali istovremeno nose i velike rizike njihovog tržišnog opstanka. Postoje ograničenja koja otežavaju primenu modela otvorenih inovacija u MSP. Ova preduzeća imaju manjak resursa, tako da se njihov period planiranja odnosi najviše na srednji rok. Realna nemogućnost MSP da dugoročno planiraju značajno umanjuje mogućnost pristupa MSP rezultatima spoljnih istraživanja. MSP nije uvek lako da uđu u održiv lanac vrednosti na tržištu, jer se fokusiraju samo na kratkoročne tržišne promocije. Veoma često ona nemaju čak ni dobro razvijeno srednjoročno planiranje tražnje usled ograničenih resursa i nedostataka potrebne mreže kontakata. Problem može da predstavlja i vremensko nepodudaranje okvira istraživanja spoljnih partnera (npr. univerziteta) sa realnim potrebama MSP što ovim često ne dozvoljava agresivan nastup na tržištu u pravom trenutku i sa pravim proizvodom. MSP često imaju probleme povezane sa finansiranjem istraživačkog procesa, nedostatak kvalifikovanih kadrova i malu mogućnost za zamenu odgovarajućih proizvoda na tržištu, ograničene mogućnosti za plasiranje proizvoda i dr. Pored ovih, postoji i veći broj drugih unutrašnjih i spoljnih prepreka inoviranju MSP, što donekle umanjuje i otežava uspešnu primenu modela otvorene inovacije, ali nikako ne umanjuje značaj njegove primene za uspešan inovativni razvoj. 


\section{SUMMARY \\ MODEL OF OPEN INNOVATION AND DEVELOPMENT OF SMALL AND MEDIUM ENTERPRISES}

In contemporary business conditions, knowledge is a key economic category, especially due to significance of its commercialisation in innovations. It is increasingly more obvious that differences in the achieved level of innovativeness considerably determine developmental possibilities of an enterprise and economy as a whole. 'Innovate or disappear', became the credo of business policy of an enterprise in the last decade of the twentieth century. Bearing in mind the fact that since then small and medium-sized enterprises have increasingly become the drivers of increase of national production and overall employment, it is clear that the necessity for improvement of their innovativeness has reached its full expression in this period. This resulted from the simple fact that innovative small and medium-sized enterprises considerably contribute to overcoming of technological gaps of national economies, i.e. contribute to their transition from lower to higher level of technological development. The paper indicates the significance of open innovation concept for the improvement of innovativeness of small and medium-sized enterprises. By providing the process of intensive exchange of knowledge, means and technologies between certain economic subjects, the concept of open innovations contributes to improvement of innovativeness in the sector of small and medium-sized enterprises as a key driver of their competitiveness in the economy of knowledge. Innovations are a powerful means for new small and medium-sized enterprises to successfully enter the market and change the current situation, thus simultaneously enabling the existing enterprises to maintain or improve their position on the market by improvement of competitiveness. Innovative small and medium-sized enterprises participate in fluctuation of knowledge within innovation systems less as passive users, but more as a significant source of knowledge.

Key words: knowledge, small and medium-sized enterprises, innovations, open innovation model

\section{LITERATURA}

1. Arnold, E., Thuriaux, B., (1997) Supporting Companies' Technological Capabilities, Technopolis report to the OECD.

2. Atkinson, R., Ezell, S., (2014). Ekonomika inovacija - utrka za globalnu prednost. Mate, Zagreb. 
3. Bogers M., Afuah A., Bastian B., (2010) Users as Innovators: A Review, Critique and Future Research Directions, Journal of Management; 36 (4)

4. Chesbrough, H., Vanhaverbeke, W., West, J., (2014) New Frontiers in Open Innovation, Oxford University Press.

5. Chesbrough, H., (2006) Open Innovation: The New Imperative for Creating and Profiting from Technology, Harvard Business School Press, Boston.

6. Curley, M., Salmelin, B., (2018) Open Innovation 2.0: The New Mode of Digital Innovation for Prosperity and Sustainability, Springer.

7. Cvetanović, D., Nikolić, M., Pokrajac, S., (2016) Impact of innovation on employment and income of small and medium-sized enterprises in the Republic of Serbia. Facta Universitatis -Economics and Organization, 13 (2)

8. Cvijić, M., Borocki, J., Lalić, D., (2012) Otvoreni modeli inovacija, Inovacije i preduzetništvo: alati za uspeh na tržištu EU, Univerzitet Singidunum, Fakultet za ekonomiju, finansije i administraciju i Centar za promociju nauke, Beograd.

9. De Backer, K., (2008) Open innovation in global networks, OECD Publishing.

10. De Bresson, C., Amesse, F., (1991) Networks of Innovators: A Review and Introduction to the Issue, Research Policy, 20

11. De Vrande, V., De Jong, J., Vanhaverbeke, W., De Rochemont, M., (2008) Open innovation in SMEs: Trends, motives and management challenges. 'SMEs and Entrepreneurship programme' financed by the Netherlands Ministry of Economic Affairs.

12. Dirckinck-Holmfeld, L., (2009) Innovation of problem based learning through ict: linking local and global experiences, International Journal of Education and Development using ICT, 5(1).

13. Drašković, V., Jovović, R., Drašković, M., (2013) Fenomenološki i paradigmatični elementi ,ekonomije znanja“, Ekonomske ideje i praksa, Ekonomski fakultet Beograd.

14. Enkel, E., Gassmann, O., Chesbrough, H., (2009) Open R\&D and open innovation: Exploring the phenomenon. $R \& D$ Management, 39(4)

15. Filipović, M., Nikolić, M., Despotović, D., (2016) Innovative small and medium-sized enterprises in the knowledge-based economy, Ekonomika preduzeća, 64 (3-4)

16. Gassmann, O., (2006), Opening up the innovation process: towards an agenda, $R \& D$ Management, 36 (3)

17. Gassmann, O., Enkel, E., Chesbrough, H., (2010) The future of open innovation. $R \& D$ Management, 40 (3), 213-221. 
18. Getejanc, V. Stanojević, Lj., (2016) Otvorene inovacije, inovacione zajednice i inovacione aktivnosti organizacija, Megatrend revija, 13 (3) 203-226

19. Greenhalgh, C., Rogers, M., (2011) Innovation, Intellectual Property and Economic Growth, Princeton University Press.

20. Grimaldi, M., Quinto, I., Rippa, P., (2013) Enabling open innovation in small and medium enterprises: A dynamic capabilities approach, Knowledge and Process Management, 20 (4)

21. Hanna, V., Walsh, K., (2002) Small firm networks: A successful approach to innovation? $R \& D$ Management, 32(3)

22. Hossain, M., (2015) A review of literature on open innovation in small and medium-sized enterprises, Journal of Global Entrepreneurship Research

23. Howells, J., James, A., Malik, K., (2003) The sourcing of technological knowledge: distributed innovation processes and dynamic change, $R \& D$ Management, 33(4)

24. Kathan, W., Matzler, K., Füller, J., Hautz, J., Hutter, K., (2014) Open innovation in SMEs: a case study of a regional open innovation platform, Problems and Perspectives in Management, 12 (1-1)

25. Li, L., Zhang, Z., Xu, M., (2016) Research on the Relationship of Innovation Capability and Operating Performance Based on Moderation of Openess, Technology and Investment, 7.

26. Lichtenthaler, U., (2011) Open Innovation: Past Research, Current Debates and Future Directions, Academy of Management Perspectives, 25 (1) 75-93.

27. Michael, S., Palandjian, T., (2004) Organizational learning in new product introductions. Journal of Product Innovation Management, 21.

28. Mroczkowski, T., (2012) The new players in life science innovation: best practices in $R \& D$ from around the world, FT Press, New Jersey.

29. Narayanan, V., (2001) Managing Technology and Innovation for Competitive Advantage. Prentice Hall Longman, New York.

30. OECD, (2000) Enhancing the competitiveness of SMEs in the global economy: Strategies and policies, Workshop 1, Enhancing the competitiveness of SMEs through innovation, Conference for Ministers responsible for SMEs and Industry Ministers, Bologna, Italy, 14-15 June 2000.

31. OECD and Eurostat, (2005) Oslo Manual - Proposed Guidelines for Collecting and Interpreting Technological Innovation Data, OECD, Paris.

32. OECD, (2010) Assessing the Effects of ICT in Education Indicators, Criteria and Benchmarks for International Comparisons: Indicators, Criteria and Benchmarks for International Comparisons, Ed. 
Scheurmans, F., Pedro, F., Joint Research Centre- European Commission, OECD.

33. Parida, V., Westerberg, M., Frishammar, J., (2012) Inbound Open Innovation Activities in High-Tech SMEs: The Impact on Innovation Performance. Journal of Small Business Management, 50(2).

34. Pokrajac, S., (2004) Tehnologizacija i globalizacija, SDPublik, Beograd.

35. Pokrajac, S., (2010) Preduzetništvo: izazovi i putevi ,kreativne destrukcije " privrede Srbije, Mašinski fakultet, Beograd.

36. Pullen, A., De Weerd-Nederhof, P., Groen, A., Fisscher, O., (2008) Configurations of external SME characteristics to explain differences in innovation performance, Proceedings of the High Technology Small Firms Conference 2008, Twente University, Netherlands.

37. Rahman, H., Ramos, I., (2011) Open Innovation in SMEs: From Closed Boundaries to Networked Paradigm, Issues in Informing Science and Information Technology, University of Minho, Guimaraes, Braga, Portugal, 7.

38. Rigby, D., Zook, C., (2002) Open-market innovation, Harvard Business Review, 80 (10).

39. Smith, D., (2010) Exploring Innovation, McGraw-Hill.

40. Sungjoo, L., Gwangman, P., Byungun Y., Jinwoo, P., (2010) Open innovation in SMEs-An intermediated network model, Research Policy, 39.

41. Švarc, J., (2009) Hrvatska u društvu znanja - prijepori i perspektive inovacijske politike, Školska knjiga, Zagreb.

42. UNESCO, Measuring innovation, (2009) Training workshop on science, technology and innovation indicators, PPT, Cairo, Egypt, 28-30, http://www.uis.unesco.org/SiteCollectionDocuments/Measuring\%20inno vation.ppt.

43. Vanhaverbeke, W., (2006) The interorganizational context of open innovation. In: Chesbrough, H., Vanhaverbeke, W. and West, J. (Eds.). Open innovation: researching a new paradigm, Oxford.

44. West, J., Gallagher, S., (2006) Challenges of open innovation: the paradox of firm investment in open-source software, $R \& D$ Management, $36(3)$.

Ovaj rad je primljen 06.05.2018., a na sastanku redakcije časopisa prihvaćen za štampu 15.06.2018. godine. 